\title{
BMJ Open Differences in burnout prevalence between clinical professionals and biomedical scientists in an academic medical centre: a cross-sectional survey
}

\author{
Erick Messias, ${ }^{1}$ Molly M Gathright, ${ }^{1}$ Emily S Freeman, ${ }^{2}$ Victoria Flynn, ${ }^{1}$ \\ Timothy Atkinson, ${ }^{3}$ Carol R Thrush, ${ }^{4}$ James A Clardy, ${ }^{1}$ Purushottam Thapa ${ }^{1}$
}

To cite: Messias E, Gathright MM, Freeman ES, et al. Differences in burnout prevalence between clinical professionals and biomedical scientists in an academic medical centre: a crosssectional survey. BMJ Open 2019;9:e023506. doi:10.1136/ bmjopen-2018-023506

- Prepublication history for this paper is available online. To view these files, please visit the journal online (http://dx.doi. org/10.1136/bmjopen-2018023506).

Received 12 April 2018 Revised 2 October 2018 Accepted 2 November 2018

Check for updates

(C) Author(s) (or their employer(s)) 2019. Re-use permitted under CC BY-NC. No commercial re-use. See rights and permissions. Published by BMJ.

${ }^{1}$ Department of Psychiatry, University of Arkansas for Medical Sciences, Little Rock, Arkansas, USA

${ }^{2}$ Faculty Centre, University of Arkansas for Medical Sciences, Little Rock, Arkansas, USA

${ }^{3}$ Department of Internal

Medicine, University of Arkansas for Medical Sciences, Little

Rock, Arkansas, USA

${ }^{4}$ Department of Surgery,

University of Arkansas for

Medical Sciences, Little Rock, Arkansas, USA

Correspondence to

Erick Messias;

elmessias@uams.edu

\section{ABSTRACT}

Objective To determine the prevalence and associated factors for personal, work-related and patient/clientrelated burnout in clinical professionals and biomedical scientists in academic medicine.

Design Prevalence survey using the Copenhagen Burnout Inventory.

Setting Mid-size academic health centre.

Participants Clinical providers $(\mathrm{n}=6489)$ and biomedical scientists $(n=248)$ were invited to complete the survey. 1646 completed responses (response rate $24.4 \%$ ) were analysed.

Primary and Secondary outcome measures Prevalence estimates and adjusted ORs (AOR) were stratified for gender, age and professional category.

Results Type of burnout varies across professional categories, with significant differences between clinicians and scientists. The prevalence of personal burnout was $52.7 \%$ (95\% Cl 50\% to 55\%), work-related burnout $47.5 \%$ ( $95 \% \mathrm{Cl} 45 \%$ to $49 \%)$ and patient/client-related burnout $20.3 \%(95 \% \mathrm{Cl} 18 \%$ to $22 \%)$. The prevalence of personal and work-related burnout was higher among women, while those aged 20-30 had a higher prevalence of all three burnout categories. Overall, clinical professionals had higher personal and work-related burnout, while biomedical scientists had higher client-related burnout. Accounting for the effects of gender and age, a significantly higher risk for personal burnout was found for physicians (AOR $1.64 ; 95 \% \mathrm{Cl} 1.3$ to 2.1 ) and nurses (AOR $1.5 ; 95 \% \mathrm{Cl} 1.03$ to 2.2). Significantly higher odds of work-related burnout were found for nurses (AOR 1.5; $95 \% \mathrm{Cl} 1.2$ to 1.9 ) and residents (AOR 1.9; $95 \% \mathrm{Cl} 1.04$ to 3.6). Basic scientists (AOR 10.0; 95\%Cl 5.7 to 17.6), physicians (AOR 2.8; 95\%Cl 1.9 to 4.1) and nurses (AOR $2.1 ; 95 \% \mathrm{Cl} 1.3$ to 3.5 ) had higher odds of patient/clientrelated burnout.

Conclusions Types of burnout are unevenly distributed in academic medical centres. Physicians have higher risk of personal and patient/client-related burnout, residents have higher risk of work-related burnout, basic scientists are at higher risk of client-related burnout and nurses have higher odds of all three types of burnout. Interventions addressing the problem of burnout in clinical environments may be inadequate to support biomedical scientists.

\section{Strengths and limitations of this study}

- First survey to compare burnout levels among clinical providers versus biomedical scientists within one academic medical centre.

- Use of the Copenhagen Burnout Inventory, a widely available and validated instrument to measure personal, work-related and patient/client-related burnout.

- Categorisation by specific professions informs the planning of targeted interventions to decrease burnout in academic medical settings.

- Potential responder and non-responder bias affecting the results; direct comparison of clinical and non-clinical providers who have very different roles in the academic mission; biomedical scientist ability to define the 'client' for the client/patient scale compared with clinical providers having a set choice of 'patient'; sample from a single academic medical centre; multicentre studies are needed to enhance generalisability.

\section{INTRODUCTION}

Academic medical centres are complex organisations with a myriad of professionals working in support of the traditional academic mission of education, healing and discovery. While representing $5 \%$ of all US hospitals, they provide $26 \%$ of all Medicaid hospitalisations, including a disproportionately high number of complex cases. ${ }^{1}$ Among the core professionals staffing academic medical centres are clinicians, including physicians, nurses, physicians in training, other healthcare providers who provide direct clinical care and biomedical scientists whose time is devoted to research and teaching. While all employees work towards the academic mission, the pressures and demands for these professionals differ in quantity and quality.

Burnout is a psychological syndrome in response to chronic job stressors conceptualised by Maslach as having three dimensions: 
Table 1 Demographic characteristics of academic health centre burnout survey respondents $n=1646,2017$

\begin{tabular}{lrr}
\hline Characteristics & No (\%) & \\
\hline Gender & & \\
\hline Male & 366 & 23.3 \\
\hline Female & 1206 & 76.7 \\
\hline Age range & & \\
\hline $20-30$ & 228 & 14.5 \\
\hline $31-40$ & 415 & 26.3 \\
\hline $41-50$ & 402 & 25.5 \\
\hline $51-60$ & 356 & 22.6 \\
\hline Over 61 & 174 & 11.0 \\
\hline Professional category & & \\
\hline Advanced practice nurse & 61 & 3.7 \\
\hline Biomedical scientist & 108 & 6.6 \\
\hline Nurse & 636 & 38.6 \\
\hline Other & 446 & 27.1 \\
\hline Physician & 194 & 11.8 \\
\hline Resident & 53 & 3.2 \\
\hline Technician & 66 & 4.0 \\
\hline Technologist & 82 & 5.0 \\
\hline
\end{tabular}

emotional exhaustion, cynicism or depersonalisation, and a lack of sense of personal efficacy. ${ }^{2}$ The Danish Project on Burnout, Motivation and Job Satisfaction created the Copenhagen Burnout Inventory (CBI) to assess burnout. This group characterises exhaustion as the primary driver affecting burnout in three realms: personal, work-related and client-related burnout. ${ }^{3}$ Healthcare has been the primary industry for research on burnout for several decades. Compared with the general population, physicians are at higher risk for symptoms of burnout and dissatisfaction with work-life balance. ${ }^{4}$ These worrisome trajectories appear early in training, with medical students, residents and early career physicians already more likely to be burned out when compared with counterparts in the general population. ${ }^{5}$ On the professional end, physician burnout is also associated with increased medical errors, decreased patient satisfaction, decreased productivity and professional effort, and increased turnover. $^{67}$

Medical specialties differ in their risk of burnout with those in the frontlines of care such as family medicine, internal medicine and emergency medicine experiencing the highest likelihood. This burnout risk also varies through the professional lifespan. Mid-career experiences the lowest satisfaction and is most likely to consider leaving medicine altogether. ${ }^{8}$ Unsurprisingly, these high levels of dissatisfaction in providers affect medical students where burnout has been associated with self-reported unprofessional conduct and less altruistic professional values among medical students. ${ }^{9}$ Medical students with burnout have also been shown more likely to agree that inappropriate prescribing behaviour was acceptable and less likely to report colleagues with unprofessional behaviours. ${ }^{10}$

Professional burnout in clinical settings is not limited to physicians or physicians in training. Nurses have also been shown to have significantly higher burnout prevalence. In a cross-sectional analysis across six countries, higher levels of nursing burnout were associated with lower ratings of the quality of care independent of nurses' ratings of practice environments. ${ }^{11}$ Increased nurse burnout is associated with lower patient satisfaction ${ }^{12}$ and higher turnover for hospital-based nurses. ${ }^{13}$ Among university hospital nurses, $86 \%$ met criteria for burnout, ${ }^{14}$ while a meta-analysis of studies on emergency nurses report that about $30 \%$ experience substantial burnout in at least one of the dimensions of the Maslach Burnout Inventory (MBI) subscales. ${ }^{15}$

Basic scientists are an integral part of academic medical centres and in recent years have experienced increased stress and decreased morale, though few studies have quantified their level of professional burnout. ${ }^{16}$ Given this context, there have been calls for more research on basic scientist burnout, an area where the burnout literature is sparse. ${ }^{17}$

The purpose of this study was to determine the prevalence and associated factors for personal, work-related and patient/client-related burnout among both clinical professionals and biomedical scientists within an academic medical centre.

\section{METHODS}

Data came from a survey sent to all employees affiliated with the clinical enterprise at our academic medical centre $(n=6489)$ and all biomedical scientist faculty in the college of medicine $(n=248)$. The survey was administered online via LimeSurvey in 2017. The University of Arkansas for Medical Sciences, where the study was conducted, is a mid-size academic health centre and it is the only academic health centre in the state.

\section{MEASURES}

The CBI was developed as part of the Danish Project on Burnout, Motivation, and Job Satisfaction (Danish acronym: PUMA). ${ }^{16}$ The CBI is a 19 -item validated tool which measures physical and emotional exhaustion as it relates to the following aspects of one's life: personal, work, and patients/clients. For each dimension (personal, work and patient/client), a score of zero indicates that an individual does not have burnout where a score of 50 or greater is considered to indicate moderate to high levels of burnout. ${ }^{16}$ The client-related questions were modified for each population in this study, as recommended by the CBI manual. For the clinical professionals, instead of 'clients', the questions referred to 'patients'. The biomedical scientists were given options to select which best represented their 'client'; those options included: 


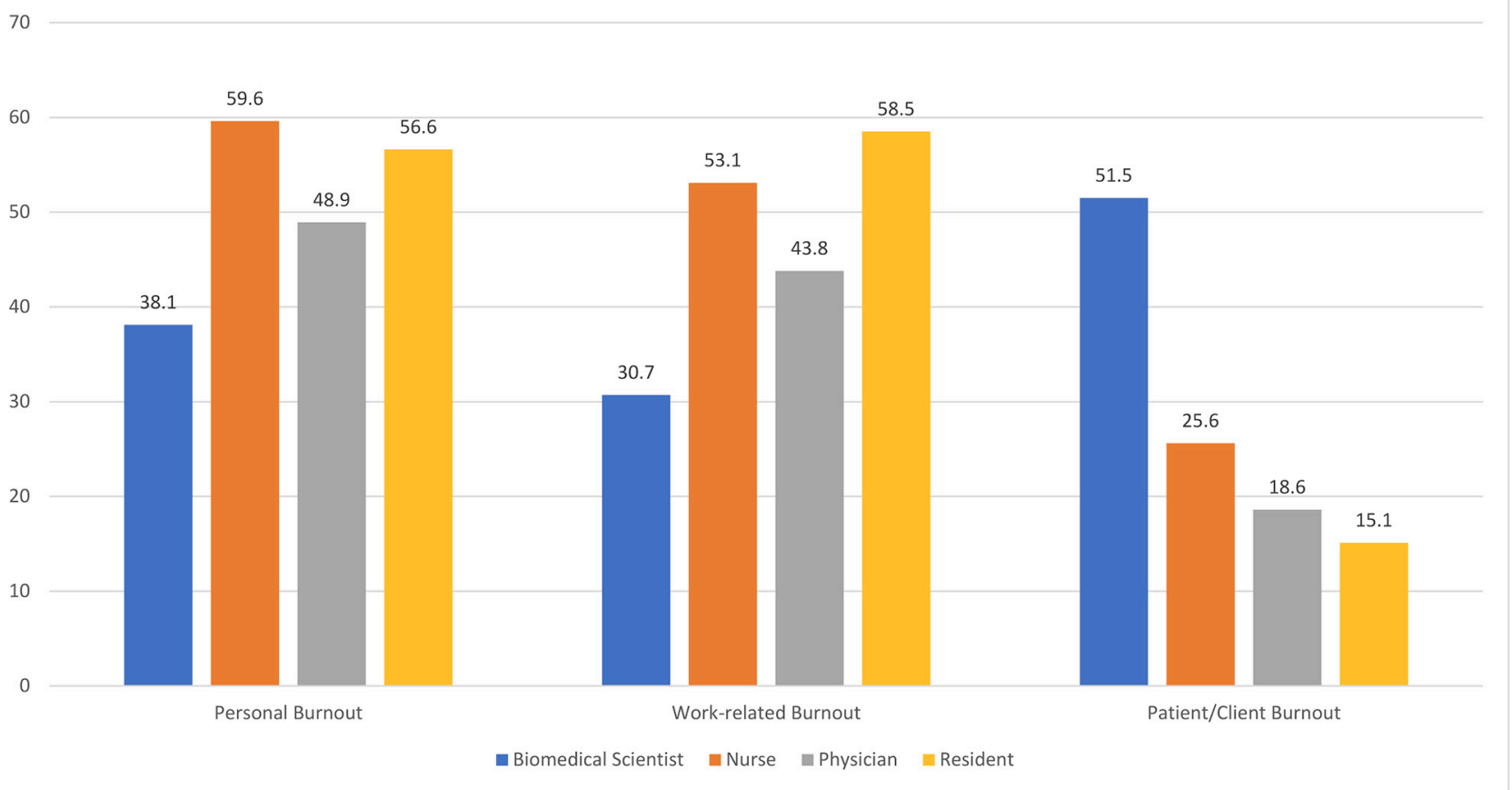

Figure 1 Prevalence of different types of burnout by professional category in academic medicine.

administrators, colleagues, funding agencies, students, and other (open for specification). The CBI's normative prevalence values, in the Danish population, for personal, work-related and client-related burnout, defined as a score of $>50$, were $22.2 \%, 19.8 \%$ and $15.9 \%$, respectively. The CBI has been shown to have high internal reliability and is associated with sickness absence, sleep problems and intention to quit. ${ }^{16}$ The CBI is publicly available, has been validated in multiple languages and has been used to assess burnout in healthcare environments. ${ }^{18-20}$ The CBI is among the valid and reliable survey instruments listed by the National Academy of Medicine Action Collaborative on Clinician Well-Being and Resilience. ${ }^{21}$ For these reasons, the CBI was used to measure burnout in these populations, rather than the MBI. While the MBI has been used in many recent studies on burnout in US healthcare workers, it is not freely available in the public domain. The survey protocol was approved as exempt by the University of Arkansas for Medical Sciences Institutional Research Board. Participation in the survey was anonymous and voluntary.

Scoring for each of the three CBI scales was calculated as the mean of items included in the scale. The Likerttype scale response options are always $=100$, often $=75$, sometimes $=50$, seldom $=25$ and never $/$ almost never $=0$. One item is scored in reverse: Do you have enough energy for family and friend during leisure time? The higher the score in each scale, the higher the level of burnout. Those with scores of 50 or greater were included in the burnout group for prevalence estimations.

For the calculation of CBI scores for professional categories, each category is reported separately except for the 'other' category where those professions with fewer than 35 individuals were subsumed. Among those professions were 1 dentist, 18 dietitians, 2 mental health paraprofessionals, 14 mental health professionals, 26 pharmacists, 1 psychologist, 26 rehab therapists, 16 respiratory therapists, 35 social workers, 8 sonographers and 299 in a variety of administrative positions.

\section{STATISTICAL ANALYSIS}

Cronbach's alpha was calculated to estimate reliability of the CBI scales. Mean CBI scores were compared using t-test and one-way analysis of variance. Prevalence differences were compared with Pearson $\chi^{2}$ and $95 \%$ CI estimates. Logistic regression models were used to estimate adjusted ORs (AORs) for personal, work-related and patient-related burnout. Reference categories for logistic models were male gender, youngest age bracket and the 'other' professional category. Analyses were done using SPSS V.24 and Stata V.12.

\section{PATIENT AND PUBLIC INVOLVEMENT}

Patients or public were not involved.

\section{RESULTS}

Demographic characteristics of survey respondents are shown in table 1 . Of the 6737 individuals invited to complete the survey, 1646 completed responses were received yielding an overall response rate of $24.4 \%$. The final sample was majority female $(76.7 \%)$, well-distributed age range, and among professional categories, the largest was nurses and advanced practice registered nurses (APRNs) (42.3\%) followed by 'other' (27.1\%) and physician $(11.8 \%)$. These proportions are similar to the 
Table 2 Prevalence of different types of burnout by demographic characteristics

\section{Prevalence $(95 \% \mathrm{Cl})$}

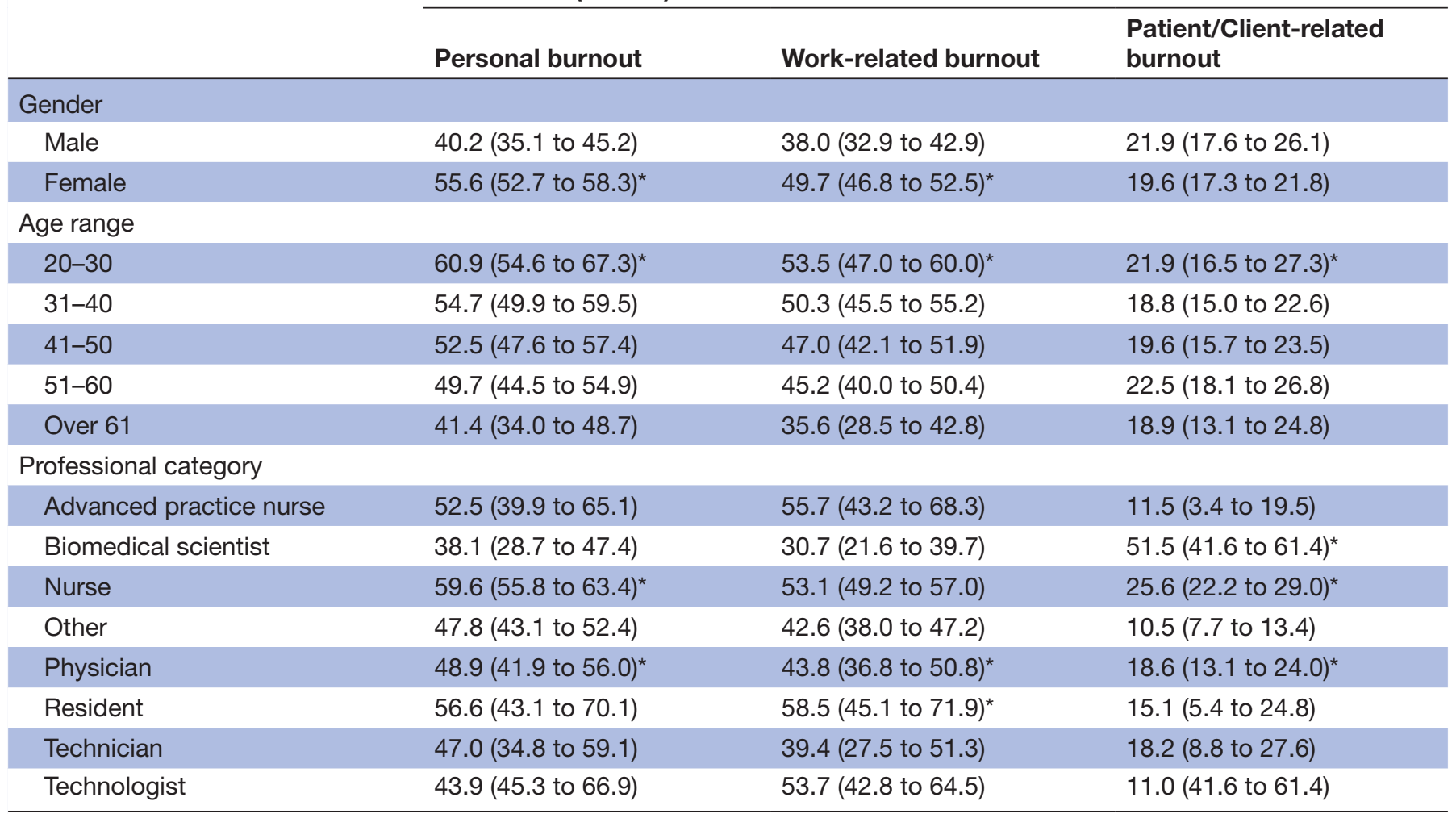

*Statistical significance in logistic regression models, see text for adjusted ORs.

distribution of professionals at the academic medical centre where the largest categories are 'other' $(54.2 \%)$, nurses and APRNs (23.7\%), and physicians (10.4\%). Basic scientist choice of 'client' was divided as follows: colleagues $(33 \%)$, funding agencies $(28 \%)$, students $(18 \%)$, administrators $(14 \%)$ and others $(7 \%)$.

\section{RELIABILITY}

Cronbach's alpha was 0.91 for the personal burnout scale, 0.89 for work-related and 0.88 for patient-related burnout, indicating high reliability. The mean burnout scores across scales were significantly correlated; Pearson correlations were 0.87 between work and personal scales, 0.51 between personal and patient/client scales and 0.56 between patient/client and work scales (all $\mathrm{p}<0.001$ ).

\section{BURNOUT LEVELS BY CBI MEAN SCORES}

The mean CBI score for the total sample was 49.2 (SD 19.9) for personal, 46.7 (SD 20.8) for work-related and 28.6 (SD 21.3) for patient/client-related burnout. In terms of gender differences, we found a statistically significant difference in mean CBI scores between men and women in all three scales $(p<0.001$ for personal and work-related and $\mathrm{p}<0.05$ for patient/client-related). Mean scores were 50.8 (SD 19.4) for women versus 42.7 (SD 20.1) for men in the personal scale; mean scores were 47.9 (SD 20.5) for women versus 41.7 (SD 20.9) for men in the work-related scale; mean scores were 27.7 (SD 21.1) for women versus 30.7 (SD 21.2) for men in the patient/client-related scale. With regard to differences by professional roles, we observed several statistically significant differences in mean CBI scores as well. Residents had the highest mean CBI score for both personal (mean 52.9 (SD 16.4)) and work-related (mean 52.6 (SD 16.5)) burnout. Basic scientists had the highest mean in patient/client-related burnout (mean 45.5 (SD 24.3)). In posthoc testing, nurses scored statistically significantly higher than physicians in personal as well as work-related burnout while basic scientists scored statistically significantly higher than any other professional group in patient/client-related burnout.

\section{PREVALENCE OF BURNOUT}

The prevalence of personal burnout in the total sample was $52.7 \%$ (95\% CI50\% to $55 \%$ ), work-related burnout was $47.5 \%$ (95\% CI $45 \%$ to $49 \%$ ) and patient/client-related burnout was $20.3 \%$ (95\% CI $18 \%$ to $22 \%$ ). These prevalence estimates differ significantly across demographic variables and are reported in table 2 . Statistically significant differences were women had a higher burnout prevalence in the personal scale (Pearson $\chi^{2}=26.6$, $\mathrm{df}=1, \mathrm{p}<0.001$ ) as well as work-related scale (Pearson $\left.\chi^{2}=15.4, \mathrm{df}=1, \mathrm{p}=0.008\right)$; nurses had the highest burnout 

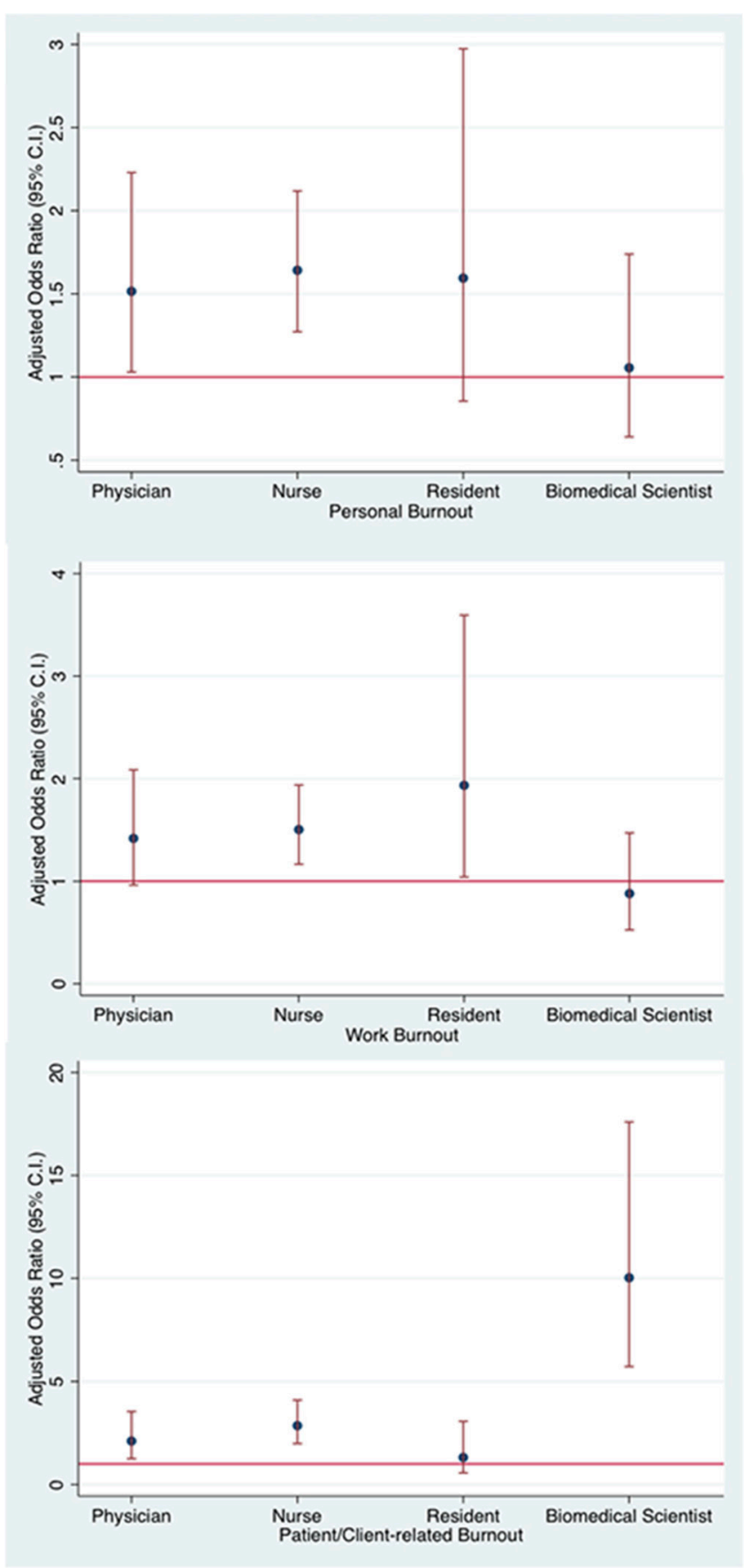

"Reference Group: "Other" category-see text for details.

Figure 2 Adjusted OR of different types of burnout by professional category in academic medicine.

prevalence in the personal scale $\left(\chi^{2}=28.1, \mathrm{df}=7, \mathrm{p}<0.001\right)$; basic scientists had the highest prevalence in the patient/ client scale $\left(\chi^{2}=105.7, \mathrm{df}=7, \mathrm{p}<0.001\right)$; residents had the highest work-related burnout prevalence $\left(\chi^{2}=19.6, \mathrm{df}=7\right.$, $\mathrm{p}=0.003$ ). In relation to age categories, those between 20 and 30 years of age had higher burnout prevalence for all three burnout subscales. The prevalence of the three types of burnout across the four largest professional categories is displayed in figure 1 .
AOR of burnout

Statistically significant AOR for personal burnout in logistic regression models were female sex with an AOR of 1.85 (95\% CI 1.4 to 2.5); age bracket in the 50s AOR of 0.64 (95\% CI 0.45 to 0.92 ) and in the $60 \mathrm{~s} \mathrm{AOR} \mathrm{of} 0.51$ (95\% CI 0.33 to 0.81 -compared with those in their $20 \mathrm{~s}$; being a nurse AOR of 1.5 (95\% CI 1.03 to 2.2) or a physician AOR of 1.64 (95\% CI 1.3 to 2.1). Logistic regression modelling of ORs for work-related burnout yielded the following significant risk and protective factors: female sex with an AOR of 1.6 (95\% CI 1.2 to 2.1); age over 60 AOR 0.56 (95\% CI 0.4 to 0.9 ); and being a nurse AOR of 1.5 (95\% CI 1.2 to 1.9$)$ or resident AOR 1.9 (95\% CI 1.04 to 3.6). Regarding patient/client-related burnout, being over 60 years of age was protective AOR of $0.5(95 \%$ CI 0.3 to 0.9 ) while nurses AOR 2.1 (95\% CI 1.3 to 3.5 ), physicians AOR 2.8 (95\% CI 1.9 to 4.1 ) and basic scientist AOR 10.0 (95\% CI 5.7 to 17.6) were at higher risk. The AORs, including some non-statistically different from the 'other category', and CIs for the four largest professional categories are displayed in figure 2.

\section{DISCUSSION}

This is the first paper to contrast personal, work-related and patient/client burnout in academic medicine including both biomedical scientists and clinical professionals. We found that in a multiprofessional sample of academic medical centre employees, the level and types of burnout vary significantly across professional roles, age groups and gender. Nurses have the highest prevalence of personal burnout, basic scientists have the highest level of patient/client-related burnout and residents have the highest degree of work-related burnout. Women have a higher prevalence of both personal and work-related burnout, while men have a higher prevalence of patient/ client-related burnout.

Proposed risk factors for personal burnout include female sex, young age (20s) and nursing and physician careers; risk factors for work-related burnout include female sex and being a nurse or a resident physician; risk factors for patient/client-related burnout include careers as a nurse, physician or basic scientist. The single statistically significant proposed protective factor for all three dimensions of burnout was age in the 60s. Previously suggested drivers for burnout include excessive workload and a lack of control of time and effort in the work place. Those of younger age, in training, and in the nursing profession are more likely to be on the frontlines of patient care and to have daily activities dictated, rather than self-directed. These factors may directly affect their sense of control or autonomy in the workplace and thus increase personal and work-related burnout. One may also propose those earlier in their training and on the frontlines of care have increased responsibility of daily tasks necessary for patient care which may or may not be as intellectually stimulating or fulfilling, also contributing to a lost sense of meaning and work and personal-related 
burnout. This possible explanation has been proposed by other burnout researchers as well. ${ }^{22}$

Adjusting for the effects of sex and age, physicians have higher odds of having personal and patient-related burnout, nurses of all types of burnout, residents of work-related burnout and biomedical scientists of patient/client burnout.

Strengths and weaknesses of the current study are important to consider in contrast with other available estimates on the prevalence of burnout in healthcare settings. Strengths of this study include being the first survey to compare burnout levels among clinical providers versus biomedical scientists within one academic medical centre; the use of the CBI, a widely available and validated instrument to measure personal, work-related and patient/ client-related burnout; and prevalence estimation by specific professional category allowing the planning of targeted interventions to decrease burnout in academic medical settings. Weaknesses of the study include potential responder and non-responder bias affecting the results; comparison of clinical and non-clinical providers who have very different roles in the academic mission; inability of biomedical scientist to define a unique 'client' for the client/patient scale compared with clinical providers having a set choice of 'patient'; using a sample from a single academic medical centre. To address some of these limitations, multicentre studies are needed to enhance generalisability.

The current results are in accordance with other studies using the CBI to measure burnout in other similar healthcare organisations. In one such study, conducted in New Zealand, among senior doctors and dentists $(n=1487)$, the prevalence of personal, work and patient-related burnout was $50 \%, 42 \%$ and $16 \%$, respectively. ${ }^{19}$ That study also found burnout to be higher among women, emergency and psychiatry specialists, and among those younger in age. ${ }^{19}$ A Taiwanese study looking across five health professions, also using the CBI, found the highest work-related burnout rate among nurses $(66 \%)$, followed by physician assistants $(61.8 \%)$, physicians $(38.6 \%)$, administrative staff $(36.1 \%)$ and medical technicians $(31.9 \%)$; it also reported higher burnout among women and those of a younger age. ${ }^{20} \mathrm{~A}$ study contrasting physician burnout in the USA versus those practising in the Netherlands found male US physicians reported more work control when compared their female counterparts, a difference not found among the Dutch. ${ }^{23}$ The original PUMA results showed significant correlations between work-related burnout rates and less job satisfaction, more quantitative demands, role-conflicts and emotional demands; those with high burnout scores also had 13.9 sick-days compared with six among those with low burnout scores. ${ }^{24}$

Our results carry consequences for those planning interventions to decrease burnout and improve engagement in healthcare organisations, in particular in academic medical centres. First, as important as physician burnout is, other professional categories should be contemplated, in particular nurses and trainees, such as residents and perhaps even medical students. Second, women have a significantly higher burnout prevalence, especially as it pertains to personal burnout. Third, there appears to be an age or cohort effect in burnout risk that should be taken in consideration when planning such interventions. Fourth, basic scientists are at increased risk of patient/ client-burnout, in particular as it pertains to funding agencies and administrators. These findings point to different sources and types of burnout in academic medicine, which will require different interventions.

Finally, the prevalence of burnout among healthcare professionals is high and constitutes a pressing challenge to be met by organisations, individuals and society at large. Identifying at risk groups is just the first of many steps already described to reduce burnout. ${ }^{24}$ It is incumbent on us to act now.

Contributors EM provided substantial contributions to the conception and design of the work, the acquisition of data for the work; the drafting of the work as well as revising it critically for important intellectual content; provided final approval of the version to be published and agreed to be accountable for all aspects of the work in ensuring that questions related to the accuracy or integrity of any part of the work are appropriately investigated and resolved. MMG, ESF, VF, TA, CRT and JAC provided substantial contributions to the conception or design of the work, the acquisition of data for the work; revising it critically for important intellectual content; provided final approval of the version to be published and agreed to be accountable for all aspects of the work in ensuring that questions related to the accuracy or integrity of any part of the work are appropriately investigated and resolved. PT provided substantial contributions to the conception or design of the work; revising it critically for important intellectual content; provided final approval of the version to be published; and agreed to be accountable for all aspects of the work in ensuring that questions related to the accuracy or integrity of any part of the work are appropriately investigated and resolved. All authors gave final approval to the submitted paper.

Funding The authors have not declared a specific grant for this research from any funding agency in the public, commercial or not-for-profit sectors.

Competing interests None declared.

Patient consent Not required.

Ethics approval The UAMS Institutional Review Board classified this study as Exempt, category 2, on 30 November 2016, protocol number 205887.

Provenance and peer review Not commissioned; externally peer reviewed.

Data sharing statement De-identified aggregate data are available upon request to the corresponding author.

Open access This is an open access article distributed in accordance with the Creative Commons Attribution Non Commercial (CC BY-NC 4.0) license, which permits others to distribute, remix, adapt, build upon this work non-commercially, and license their derivative works on different terms, provided the original work is properly cited, appropriate credit is given, any changes made indicated, and the use is non-commercial. See: http://creativecommons.org/licenses/by-nc/4.0/.

\section{REFERENCES}

1. Grover A, Slavin PL, Willson P. The economics of academic medical centers. N Engl J Med 2014;370:2360-2.

2. Maslach C. Job Burnout: New Directions in Research and Intervention. Current Directions in Psychological Science 2003;12:189-92.

3. Kristensen TS, Borritz M, Villadsen E, et al. The copenhagen burnout inventory: a new tool for the assessment of burnout. Work Stress 2005;19:192-207.

4. Shanafelt TD, Boone S, Tan L, et al. Burnout and satisfaction with work-life balance among US physicians relative to the general US population. Arch Intern Med 2012;172:1377-85

5. Brazeau CM, Shanafelt T, Durning SJ, et al. Distress among matriculating medical students relative to the general population. Acad Med 2014;89:1520-5. 
6. Shanafelt TD, Oreskovich MR, Dyrbye LN, et al. Avoiding burnout: the personal health habits and wellness practices of US surgeons. Ann Surg 2012;255:625-33.

7. Shanafelt TD, Noseworthy JH. Executive leadership and physician well-being: nine organizational strategies to promote engagement and reduce burnout. Mayo Clin Proc 2017;92:129-46.

8. Dyrbye LN, Varkey P, Boone SL, et al. Physician satisfaction and burnout at different career stages. Mayo Clin Proc 2013;88:1358-67.

9. Dyrbye LN, Massie FS, Eacker A, et al. Relationship between burnout and professional conduct and attitudes among US medical students. JAMA 2010;304:1173-80.

10. Dyrbye LN, West CP, Satele D, et al. A national study of medical students' attitudes toward self-prescribing and responsibility to report impaired colleagues. Acad Med 2015;90:485-93.

11. Poghosyan L, Clarke SP, Finlayson M, et al. Nurse burnout and quality of care: cross-national investigation in six countries. Res Nurs Health 2010;33:288-98.

12. Vahey DC, Aiken LH, Sloane DM, et al. Nurse burnout and patient satisfaction. Med Care 2004;42(2 Suppl):II57-57.

13. Coomber B, Barriball KL. Impact of job satisfaction components on intent to leave and turnover for hospital-based nurses: a review of the research literature. Int J Nurs Stud 2007;44:297-314.

14. Mealer M, Burnham EL, Goode CJ, et al. The prevalence and impact of post traumatic stress disorder and burnout syndrome in nurses. Depress Anxiety 2009;26:1118-26.

15. de Paiva LC, Canário ACG, de Paiva China ELC, et al. Burnout syndrome in health-care professionals in a university hospital. Clinics 2017;72:305-9.
16. Holleman WL, Cofta-Woerpel LM, Gritz ER. Stress and morale of academic biomedical scientists. Acad Med 2015;90:562-4.

17. Holleman W, Gritz ER. Biomedical burnout. Nature 2013;500:613-4.

18. Wright JG, Khetani N, Stephens D. Burnout among faculty physicians in an academic health science centre. Paediatr Child Health 2011;16:409-13.

19. Chambers CN, Frampton CM, Barclay M, et al. Burnout prevalence in New Zealand's public hospital senior medical workforce: a crosssectional mixed methods study. BMJ Open 2016;6:e013947.

20. Chou LP, Li CY, Hu SC. Job stress and burnout in hospital employees: comparisons of different medical professions in a regional hospital in Taiwan. BMJ Open 2014;4:e004185.

21. National Academy of Medicine. Valid and reliable survey instruments to measure burnout, well-being, and other work-related dimensions national academy of medicine. https://nam.edu/valid-reliable-surveyinstruments-measure-burnout-well-work-related-dimensions/ (Cited 2 Feb 2018).

22. Maslach C, Leiter MP. Early predictors of job burnout and engagement. J Appl Psychol 2008;93:498-512.

23. Linzer M, Visser MR, Oort FJ, et al. Predicting and preventing physician burnout: results from the United States and the Netherlands. Am J Med 2001;111:170-5.

24. Borritz M, Rugulies R, Bjorner JB, et al. Burnout among employees in human service work: design and baseline findings of the PUMA study. Scand J Public Health 2006;34:49-58. 